\title{
Fluid Identification Method of the Tight Sandstone Gas Reservoir Based on Gassmann Equation
}

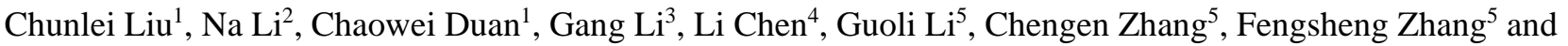 \\ Zhengquan Guo ${ }^{6}$ \\ ${ }^{1}$ Logging application research institute of CNPC Logging, Xian 710077, China \\ ${ }^{2}$ Huabei branch of CNPC Logging, Renqiu 062550, China \\ ${ }^{3}$ Exploration and development research Institute of Petrochina Qinghai Oilfield Company, Dunhuang 736202, China \\ ${ }^{4}$ Changqing branch of CNPC Logging, Xian 710200, China \\ ${ }^{5}$ Logging application research institute of CNPC Logging, Xian 710077, China \\ ${ }^{6}$ Exploration and development research Institute of Petrochina Qinghai Oilfield Company, Dunhuang 736202, China
}

\begin{abstract}
The tight sandstone gas reservoir in Altun region of the Qaidam Basin has the characteristics of low porosity and low permeability, low maturity, strong heterogeneity and complex pore structure. It causes the resistivity to react weakly to the fluid, it is not obvious that the conventional explanation method can distinguish the effect of the fluid property, and the difficulty of obtaining the saturation value is more difficult. Gas reservoir cause different change of the speed of sound wave ,amplitude and rock mechanics parameters, so on the basis of Gassmann theory equation we use core calibration logging, combined with the density curve and extraction of compressional wave slowness time and shear wave slowness time, build identification method of the pore fluid volume modulus and model of gas saturation based on elastic modulus, and compared with compressional wave and shear wave velocity ratio method, elastic modulus of single parameter method. This method can avoid rock matrix information, more accurately identify the reservoir pore fluid properties, and solve the electric logging problems in fluid identification. It adds a kind of method for the tight sandy gravel reservoir evaluation, and in the actual application good results have been achieved.
\end{abstract}

Keywords-gassmann equation; elastic modulus; fluid identification; array sonic wave; the tight sandstone gas reservoir

\section{INTRODUCTION}

The main methods for the identification of gas in the tight sandy gravel reservoir are crossplot method[1], three porosity specific value and difference method as in [2], compressional wave and shear wave velocity ratio method as in [3-5], single parameter elastic modulus method as in [6-8], shift spectrum method and difference spectrum method as in [9], the calculation methods of gas saturation mainly include the neutron density overlapping difference method as in [10], W-S model method as in [11], double saturation method as in [12] and $J$ function method as in [13-14]. The gas reservoir of the tertiary Lulehe formation in Qianniudong area of the Altun mountains in Qaidam basin is a lithologic condensate reservoir under the tectonic background, a coarse detrital sedimentary system in the alluvial fan-alluvial plain, rapid phase change, poor lateral contrast, low maturity of reservoir structure and composition and high mud content. With porosity of $3-14 \%$, mean value of $5.8 \%$, permeability of $0.02-1.56 \mathrm{mD}$ and average value of $0.14 \mathrm{Md}$, it is a low-porosity and low-permeability reservoir. The pore structure mainly consists of primary intergranular pores and secondary dissolution pores, and the pore structure is general, with high displacement pressure and micro throat. That's why the electric logging can't accurately identify the gas reservoir. In the present normal and nonelectric evaluation method is generally effective, and it's very difficult to calculate the gas saturation. On the basis of Gassmann theory equation we use core calibration logging, combined with the density curve and extraction of compressional wave slowness time and shear wave slowness time, according to the the different volume modulus of gas and water, and build gas identification method of the pore fluid volume modulus and model of gas saturation based on elastic modulus.Compared with the traditional method, this method can avoid the influence of factors such as tight reservoir and complex pore structure, and can evaluate gas reservoir qualitatively and quantitatively.

\section{PARAMETER CHARACTERISTICS OF GAS IN RESERVOR}

The sandy gravel reservoir is characterized by low porosity, low permeability and strong heterogeneity. The influence of complex pore structure on resistivity may be much greater than that of reservoir fluid type on resistivity. It causes that that difference between the resistivity of gas and water is not obvious, It is simple to use resistivity to identify that poor effect of air and water in this area, so the non-electric method of array sonic logging is of special advantage. Experiment study shows that parameters such as volume modulus, poisson's ratio are the sensitive parameters of gas saturation in the reservoirs, and volume modulus, compression coefficient, density and sound wave speed of the gas and the corresponding values of oil and water there are orders of magnitude difference. As shown in the following table, when the reservoir contains gas, the $K_{f}$ value of the volume modulus of pore fluid is far less than that of oil and water to identify gas and water. 

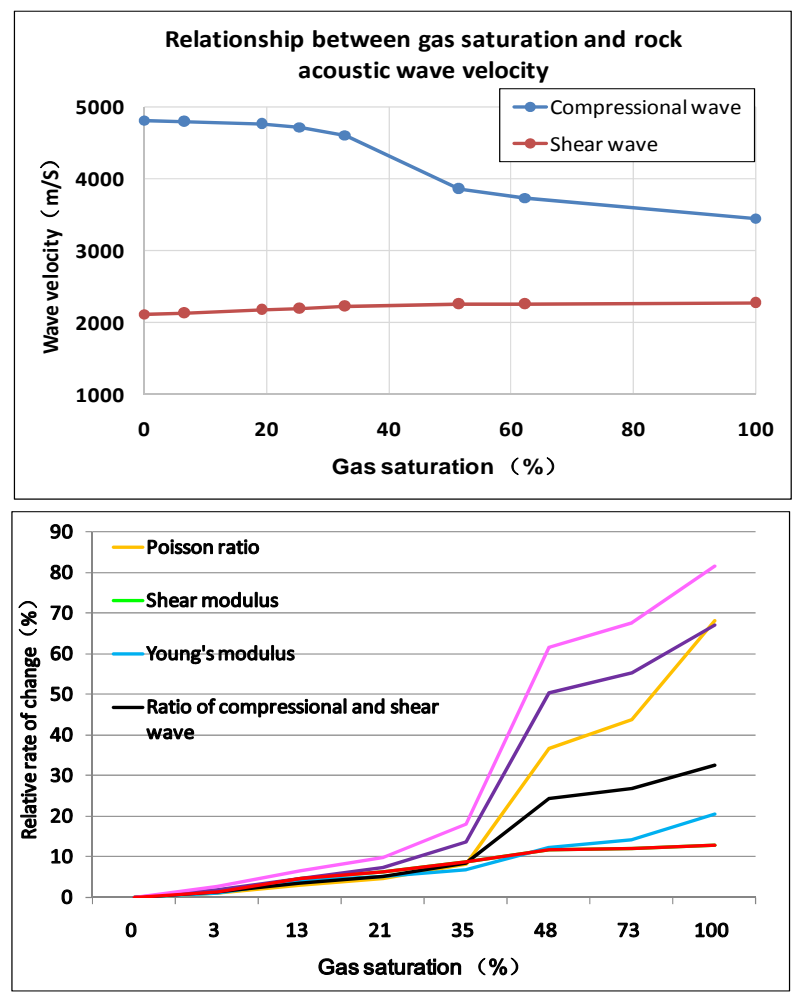

FIGURE I. RELATIONSHIP BETWEEN ELASTIC PARAMETER AND ACOUSTIC WAVE VELOCITY IN DIFFERENT GAS SATURATION

TABLE I. THEORETICAL PARAMETER VALUES OF DIFFERENT FLUID

\begin{tabular}{|c|c|c|c|}
\hline & Oil & Gas & Water \\
\hline Bulk modulus(GPa) & 1.00 & 0.05 & 2.60 \\
\hline Compression coefficient(GPa $^{-1}$ ) & 0.837 & 18.051 & 0.444 \\
\hline Density(g/cm3) & 0.83 & 0.121 & 1.0 \\
\hline Sound velocity(m/s) & 1200 & 629.7 & 1500 \\
\hline
\end{tabular}

\section{Traditional ARray ACOUSTIC LOGging MEthoD FOR IDENTIFICATION OF GAS LAYERS}

\section{A. The Envelope Area Method for Compressional Wave}

Slowness Time and Shear Wave Slowness Time

Principle: when there is natural gas in the rock, the compressional wave speed is obviously smaller, and compressional wave slowness time increases. The shear wave speed and shear wave slowness time are basically the same, and the time difference of the shear wave is basically the same. Whether the rock contains natural gas can be identified qualitatively by the size of the envelope formed by two curves.

\section{B. The Envelope Area Method for Poisson's Ratio and Young's Modulus}

Principle: when natural gas is saturated in rock, formation compression coefficient will increase, poisson's ratio and young's modulus will decrease, and the envelope area formed by two curves can also be identified qualitatively.

\section{Applicability of the Two Methods}

Whether it is the envelope area method for compressional wave slowness time and shear wave slowness time, or the envelope area method for Poisson's ratio and young's modulus, it is essentially obtained through the transformation of the pwave and s-wave extracted by array acoustic logging, and the p-wave and s-wave extracted are the response of formation information. It includes information about both the rock skeleton and the pore fluid, and as we know, when we do reservoir fluid characterization, what we need is information about the pore fluid, therefore, these two methods have some limitations in the evaluation of the sandy gravel reservoir with diverse lithology and relatively complex pore structure.

\section{The Theoretical Basis of Gassmann Equation}

Rocks can be seen as a collection of minerals and pore fluids. In order to facilitate, intuitively and effectively conduct research, rocks can be theoretically described as an "equivalent body", so that an effective petrophysical model can be established. We refer to the main parameters described as "effective elastic modulus". The basic assumption of the Gassmann equation is that the fluid (liquid, gas, or mixture) fills all of the pores; Rock or porous media (matrix and skeleton) are uniformly isotropic at a macroscopic level; All pores are connected or interconnected.

$$
\frac{\mathrm{K}_{\mathrm{sat}}}{\mathrm{K}_{\mathrm{ma}}-\mathrm{K}_{\mathrm{sat}}}=\frac{\mathrm{K}_{\mathrm{dry}}}{\mathrm{K}_{\mathrm{ma}}-\mathrm{K}_{\mathrm{dry}}}+\frac{\mathrm{K}_{\mathrm{f}}}{\phi\left(\mathrm{K}_{\mathrm{ma}}-\mathrm{K}_{\mathrm{f}}\right)}
$$

Formula (1) is the famous Gassmann equation, where: $K_{\text {sat }}$ formation volume modulus, $\Phi$ porosity, $K_{\text {ma }}$ skeleton volume modulus and $\mathrm{K}_{\mathrm{dry}}$ rock volume modulus. $\mathrm{K}_{\mathrm{f}}$ volume modulus of pore fluid.

\section{Application of GASSMANn EquATion In LOGGing EVALUATION}

According to the above Gassmann equation, in order to obtain the pore fluid volume modulus reflecting fluid properties, it is necessary to obtain some parameters such as dry rock volume modulus, dry rock shear modulus, rock porosity, particle density and fluid volume modulu. These parameters are normally measured in the lab, and if not, they can be calculated by logging or empirical equations.

\section{A. Volume Modulus of Rock Matrix}

If known mineral components of the reservoir rock, the effective skeleton volume modulus $K_{\text {ma }}$ can be calculated through the VR-H model, the results are obtained by the arithmetic mean of mean equal strain model and mean equal stress model.

In 1910, Voigt obtained the mean equal strain model by studying the crystal properties. The model has two assumptions, First, assumes that the crystal lattice orientation in the direction parallel to the applied stress. Second, the minerals in the rock are aligned parallel to the stress direction. The volume modulus of rock matrix is obtained by the following formula:

$$
\mathrm{K}_{\mathrm{V}}=\sum_{\mathrm{i}=1}^{\mathrm{N}} \mathrm{K}_{\mathrm{i}} \cdot \mathrm{V}_{\mathrm{i}}
$$


Where, $K_{v}$ is the volume modulus of rock matrix, $K_{i}$ is the volume modulus of the ith mineral, and $V_{i}$ is the percentage of the ith mineral in the rock volume.

The mean equal stress model is similar to the above model, which was proposed by Reuss in 1929. This model assumes that the mineral in the rock is perpendicular to the stress, and the volume modulus of the rock matrix is expressed as follows

$$
\mathrm{K}_{\mathrm{R}}^{-1}=\sum_{\mathrm{i}=1}^{\mathrm{N}} \mathrm{K}_{\mathrm{i}}^{-1} \cdot \mathrm{V}_{\mathrm{i}}
$$

Where: $\mathrm{K}_{\mathrm{R}}^{-1}$ as the reciprocal of the volume of rock matrix modulus, $\mathrm{K}_{\mathrm{i}}^{-1}$ as the reciprocal of the volume modulus of the ith mineral.

In 1952, Hill proposed VR-H model through the study of the above two models, that is, the arithmetic mean root is calculated for the result of the calculation of the two models, and in 1992 Wang and Nur verified the actual effect of the VR$\mathrm{H}$ model through a large amount of experimental data.

$$
\mathrm{K}_{\mathrm{ma}}=\frac{\mathrm{K}_{\mathrm{V}}+\mathrm{K}_{\mathrm{R}}^{-1}}{2}
$$

In 1998, Mavko et al. measured the volume modulus and density of various minerals in a mineral test. The results are shown in the table below.

\section{TABLE II. THEORETICA PARAMETER VALUES OF DIFFERENT MINERALS}

\begin{tabular}{|c|c|c|}
\hline Mineral & Bulk Modulus(GPa) & Density(g/cm3) \\
\hline Coal & 5 & 1.4 \\
\hline Clay & 25 & 2.55 \\
\hline Halite & 25 & 2.16 \\
\hline Quartz & 40 & 2.65 \\
\hline Anhydrite & 54 & 2.98 \\
\hline Calcite & 71 & 2.71 \\
\hline Plagioclase & 76 & 2.63 \\
\hline Dolomite & 80 & 2.87 \\
\hline
\end{tabular}

In logging interpretation, there are two methods to determine mineral component content. One is to obtain the relationship between mineral content and logging curve through whole-rock analysis, and the model of mineral content was established by mathematical regression method, then the mineral component content was obtained in the whole well. Secondly, the content of each element is obtained by formation element logging, and then the content of each mineral component is acquired.

\section{B. Volume Modulus of Dry Rock}

There are two ways to obtain elastic modulus of dry rocks:

1) Direct measurement method is to calculate the volume modulus of dry rock by the formula in the laboratory by measuring the speed of the compressional wave and shear wave, density of dry rock sample.

$$
\mathrm{K}_{\text {dry }}=\rho_{\text {dry }}\left(v_{\text {pd }}^{2}-\frac{4}{3} v_{\text {sd }}^{2}\right)
$$

In the equation: $V_{\mathrm{pd}}$ is the compressional wave speed of dry rock samples; $V_{\text {sd }}$ is the shear wave speed of dry rock samples; $\rho_{\text {dry }}$ is the density of dry rock samples.

\section{2) Biot coefficient method}

The Biot coefficient method is a function of the rock skeleton volume modulus $\mathrm{K}_{\mathrm{ma}}$ and the dry rock volume modulus $\mathrm{K}_{\mathrm{dry}}$ :

$$
\mathrm{K}_{\mathrm{dry}}=(1-\beta) \mathrm{K}_{\mathrm{ma}}
$$

$\beta$ evaluated between 0 and 1 , it is related to porosity, which can reflect the relationship between pore pressure and skeleton stress.

In this study, the elastic modulus of dry rock was firstly calculated through the rock wave velocity experiment with different saturations, and the matrix volume modulus was obtained through the whole-rock analysis, and get $\beta$ by fitting, then the relation between this and core porosity was obtained by comparing with core porosity, as shown in FIG. 3 and FIG. 2.
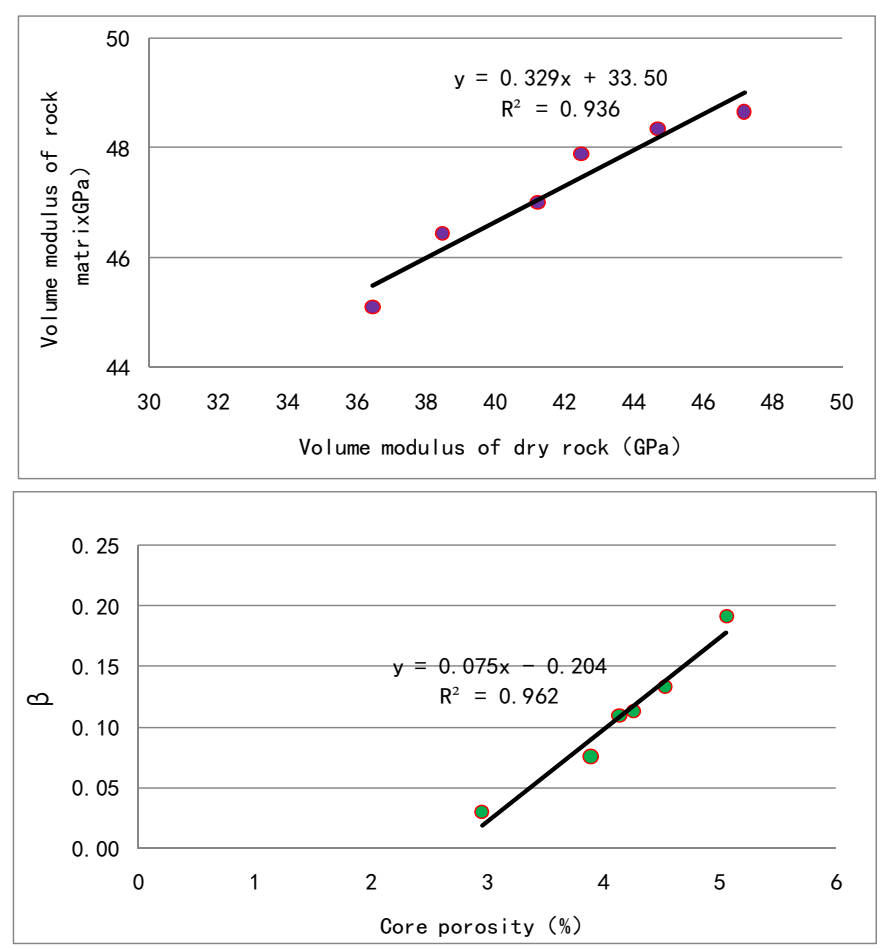

FIGURE II. THE RELATIONSHIP OF FOUR KINDS OF PARAMETERSVOLUME MODULUS OF FORMATION

According to the density value in the conventional logging data, the value of compressional wave speed and shear wave speed from the array sonic logging, and the elastic modulus method of dry rock is obtained by combining the Gassmann equation. The relationship between compressional wave speed, shear wave speed, rock density and formation volume modulus is as follows 


$$
\mathrm{K}_{\mathrm{sat}}=\rho_{\text {sat }}\left(v_{\mathrm{p}}^{2}-\frac{4}{3} v_{\mathrm{s}}^{2}\right)
$$

Where: $\mathrm{K}_{\mathrm{sat}}$ formation volume modulus; $\mathrm{V}_{\mathrm{p}}$ is the formation compressional wave speed. $V_{s}$ is the the formation shear wave speed. $\rho_{\text {sat }}$ is the density of the formation.

\section{Volume Modulus of Fluid in the Pore}

Gassmann, Murphy et al. pointed out that the volume modulus of porous media and fluid-saturated at low frequencies satisfies the following relationship:

$$
\mathrm{K}_{\mathrm{sat}}=\mathrm{K}_{\mathrm{P}}+\mathrm{K}_{\mathrm{dry}}
$$

Where: $K_{\text {sat }}$ formation volume modulus; $K_{p}$ is defined as a fluid property factor; $\mathrm{K}_{\mathrm{dry}}$ is the volume modulus of dry rock; $\mathrm{K}_{\mathrm{f}}$ is the volume modulus of pore fluid..

The relation between $K_{p}$ and pore fluid volume modulus and rock skeleton volume modulus is as follows:

$$
\mathrm{K}_{\mathrm{p}}=\frac{\beta^{2}}{\left(\frac{\beta-\phi}{\mathrm{K}_{\mathrm{ma}}}-\frac{\phi}{\mathrm{K}_{\mathrm{f}}}\right)}
$$

The volume $\beta$ modulus of dry rock is calculated by using the Biot coefficient method, The Biot coefficient is introduced to establish a relationship between the dry rock volume modulus and the matrix volume modulus. $K_{d r y}=(1-\beta) K_{m a}$.

By combining equations (6), (7), (8)and (9), the volume modulus of pore fluid can be obtained as follows:

$$
\mathrm{K}_{\mathrm{f}}=\frac{\phi \mathrm{K}_{\mathrm{ma}} \mathrm{K}_{\mathrm{p}}}{\beta^{2} \mathrm{~K}_{\mathrm{ma}}-(\beta-\phi) \mathrm{K}_{\mathrm{p}}}
$$

\section{DETERmine Gas Saturation QuANTITATIVELY}

The characteristics of complex pore structure on the influence of resistivity may outweigh the reservoir fluid type influence on resistivity, and conductive model such as archie formula effect is poorer, When the reservoir contains gas, the wave velocity, the speed and amplitude of sound wave and rock mechanics parameters will have different effects, such as sound wave information makes the gas of the obvious difference between oil and water, Therefore, based on the
Gassmann equation, a quantitative calculation model of gas saturation is established by using the pore fluid volume modulus.

Suppose the rock is saturated with gas and water. According to Wood formula,

$$
\frac{1}{K_{f}}=\frac{S_{g}}{K_{g}}+\frac{S_{W}}{K_{w}}
$$

Where: $K_{g}$ is the volume modulus of natural gas, $K_{w}$ is the volume modulus of water, $\mathrm{S}_{\mathrm{g}}$ is gas saturation, and $\mathrm{S}_{\mathrm{w}}$ is water saturation.

$$
\mathrm{S}_{\mathrm{g}}+\mathrm{S}_{\mathrm{w}}=1
$$

By combining equations (12) and (13). The gas saturation $\mathrm{S}_{\mathrm{g}}$ of the solution is:

$$
S_{g}=\frac{K_{g} K_{w}-K_{f} K_{g}}{K_{f} K_{w}-K_{f} K_{g}}
$$

\section{EXAMPLES OF INTERPRETATION RESULT}

Figure 3 is the pore fluid volume modulus and the gas saturation explained the results of $\mathrm{XX}$ well, In the first perforation segment below, the young's modulus and poisson's ratio envelope method show some overlapping areas, but the value of the pore fluid bulk modulus is bigger, can't see the overlap envelope area, and gas saturation is $22 \%$ by integrated interpretation water. Gas fracturing test, the result is water. And the second perforation segment above, you can see that there is some envelope area in the envelope area method for compressional wave slowness time and shear wave slowness time or for Poisson's ratio and Young's modulus, but the effect was not obvious, but the calculation of the pore fluid bulk modulus obviously decreases, through it to intersect with that intermediate variable fluid property factor, a significant envelope area formed can be seen, it is good indication of gas bearing, calculated gas saturation is $44 \%$ by integrated interpretation oil-water. Conventional gas test, 3mm oil nozzle, no liquid, trace gas. After fracturing, $10 \mathrm{~mm}$ oil nozzle, producing gas $42260 \mathrm{~m}^{3} / \mathrm{d}$ and water $337.49 \mathrm{~m}^{3} / \mathrm{d}$. The interpretation conclusion is consistent with the gas test conclusion.

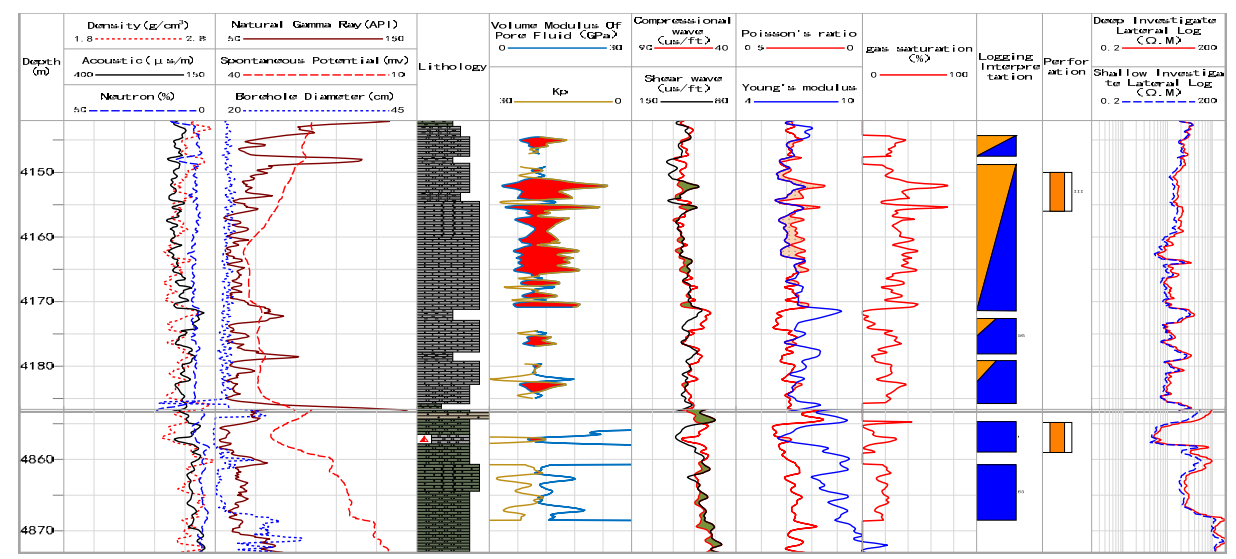

FIGURE III. AN EXAMPLE OF INTERPRETATION RESULT IN XX WELL 


\section{CONCLUSION}

This method can directly obtain the fluid information in the pore, which is more effective in "removing the skeleton" information. The scale can be carried out by core experiment, and by pore fluid bulk modulus, combined with the Wood model, quantitative calculation of gas saturation model is established. It can solve the problem in electric logging fluid identification, add a kind of method of non-electrical method in gas sandy gravel reservoir evaluation and achieve good results in practice.

\section{ACKNOWLEDGEMENTS}

Supported by The Science and Technology Major Project of Petro China Company Limited (2016E-0108).

\section{REFERENCES}

[1] YJ Zhang, DN Gu, and SB Ma, “The application of Array acoustic logging data in the identification of tight sandstone gas reservoirs in tuha oilfield,” J Logging technology. 2012, 36(2), pp.175-178.

[2] Q Zhang, “Application of three porosity overlapping method, three porosity difference and ratio method in identification of gas reservoir in yongchujie gas field in baoshan basin," J Journal of petroleum and natural gas. 2010, 32(4), pp.90-93.

[3] XP Chen, SH Liu, "Introduction to Gassmann equation,” J China offshore oil and gas (geology). 1996, 10(2), pp.122-127.

[4] KG Chen, WW Wang, and JJ Guo, "Study on acoustic absorption characteristics of homogeneous gas layer sandstone,” J Logging technology. 2008, 32(2), pp.152-163.

[5] ZM Liu, "Using the normal source of the all-wave logging to identify natural gas,” J Natural gas industry. 2005, 25(6), pp.35-36

[6] SH Wang, $\mathrm{CH} \mathrm{Li}$, and GH Zhang, "Comprehensive identification of gas by array acoustic logging,” J Foreign logging. 2012, 5, pp.12-14..

[7] ZJ Wang, CL Li, and ZB Zhang, "Using the array sonic logging to evaluate low permeability sandstone reservoirs,” J Foreign logging. 2010, 2, pp.45-47.

[8] SD Yang, JW Zhao, and WJ Tang "A new method for identification of gas reservoirs with low porosity and permeability,” J Logging technology. 2005, 29(1), pp.43-45.

[9] FL Hu, CC Zhou, and CL Li, "Nuclear magnetic resonance logging (NMR) is used to construct fluid identification technology," Petroleum exploration and development. 2014, 01, pp.244-252.

[10] JY Zhang, SR li, and LB Wang, “A new method for calculating gas saturation in low resistance shale gas layer,” J Natural gas industry. 2017 37(4), pp.34-38.

[11] D Wang, JZ Qi, and X Chen, "Genetic analysis and quantitative evaluation of low resistivity gas layer in $\mathrm{N}$ gas field in east China sea," J Complex reservoirs. 2017, 10(4), pp.8-12.

[12] X Chen, CQ Gao, “Application of double saturation method in identification of low saturation gas layer in SanHu area," J Oil geophysical prospecting. 2011, 50(1), pp.93-97.

[13] CR Shao, PF Zhang, and FM Zhang, "The J function is used to improve the accuracy of gas saturation log evaluation of tight sandstone,” $\mathrm{J}$ Journal of China university of petroleum (natural science edition). 2016, 40(4), pp.57-61.

[14] WH Lang, "The Determination of Thermal Maturity in Potential Source Rocks Using Interval Transit Time Interval Velocity,” Log Analyst. 1994, 35, pp.47-59. 